\title{
Examining Trends of Criteria Air Pollutants: Are the Effects of Governmental Intervention Transitory?
}

\author{
JUNSOO LEE ${ }^{1, *}$ and JOHN A. LIST ${ }^{2}$ \\ ${ }^{1}$ Department of Economics, University of Alabama, Box 870224, Tuscaloosa, AL 35487, USA, and \\ University of Central Florida, USA; ${ }^{2}$ University of Maryland and NBER; \\ *Author for correspondence (e-mail: jlee@cba.ua.edu)
}

Accepted 28 October 2003

\begin{abstract}
Despite its growth in other areas of economics, time series econometric methods have not been widespread in the area of environmental and resource economics. We illustrate one use of time series methods by examining the time path of US nitrogen oxide $\left(\mathrm{NO}_{\mathrm{x}}\right)$ emission data over the period 1900-1994. The analysis highlights that proper time series methods can aid in optimal regulatory policy as well as developing empirical verification of theories put forth to explain economic phenomena. In addition, several interesting results emerge. First, we find that the emissions series contains both a permanent and random component. Second, if one attributed all of the emissions reductions to regulatory policy, intervention analysis suggests that the 1970 Clean Air Act (CAA) did not merely have transitory effects, but permanently influenced the $\mathrm{NO}_{\mathrm{x}}$ emission path. In terms of total regulatory impact, an upper bound on the emissions saved due to the 1970 CAA is in the range of $27 \%-48 \%$.
\end{abstract}

Key words: emissions, intervention analyses, time-series models

JEL classifications: Q28, C22

\section{Introduction}

Examining the time-series properties of real variables, such as GDP, to determine whether they follow deterministic or stochastic trends has become commonplace amongst macroeconomists. Yet nearly two decades after Nelson and Plosser's (1982) seminal study regarding stationarity of macroeconomic variables, analysis of environmental time-series data has been sparse. ${ }^{1}$ Although data availability represents a serious roadblock, a better understanding of the time paths of pollutants can help shape the development and empirical verification of theories put forth to explain the temporal behavior of emissions. Accuracy of predicting pollution paths has far reaching implications such as aiding in the development of optimal abatement strategies and multilateral bargaining strategies.

Our goal in this paper is to highlight recent innovations in time series econometrics by presenting a dynamic characterization of US emissions for one criterion 
air pollutant-nitrogen oxide $\left(\mathrm{NO}_{\mathrm{x}}\right)$-while simultaneously providing an external validity check of the recent analytically intensive self-evaluation carried out by the Environmental Protection Agency (EPA). Intuition implies that $\mathrm{NO}_{\mathrm{x}}$ emissions may have both a permanent and random component. ${ }^{2}$ In such a circumstance, EPA mandates can have a permanent and/or a temporary effect on emission levels. If governmental mandates influence only the temporary component, they are futile in shaping long-run pollution trends since pollution flows will revert to their mean. Conversely, if policies affect the permanent component, they are influencing long-term emission growth paths.

We use a unique data set that is a compilation of US emission data from 19001994 to perform a battery of tests to characterize the stochastic nature of $\mathrm{NO}_{\mathrm{x}}$ emission flows. Our empirical findings support the hypothesis that emissions of $\mathrm{NO}_{\mathrm{x}}$ follow a unit root process. As discussed in more detail below, this finding has significant implications for the large number of studies that have found a Kuznets curve relationship between environmental quality and income. We also find that EPA mandates have had a permanent effect on emission flows-turning the difference stationary process into a trend stationary process. We conclude by estimating the emissions saved due to the Clean Air Act of 1970. Although our empirical techniques are much less labor-intensive than EPA's, if one attributed all of the emissions reductions to regulatory policy, our intervention analysis estimates reductions in the range of 27\%-49\%, which are higher than those of EPA's (1997) recent self-assessment. ${ }^{3}$

\section{Data and Econometric Methods}

As an indicator of previous domestic emission flows, we analyze annual US per capita $\mathrm{NO}_{\mathrm{x}}$ emissions over the period 1900-1994. We selected $\mathrm{NO}_{\mathrm{x}}$ emissions for our exploratory probe for two reasons. First, $\mathrm{NO}_{\mathrm{x}}$ was one of the original five criteria air pollutants targeted for reduction by the Federal government in 1970. $\mathrm{NO}_{\mathrm{x}}$ emissions were targeted due to the numerous deleterious effects they have on the general public-including respiratory illness, decreased pulmonary functions, immunological changes, and decreased visibility. Besides many primary effects, $\mathrm{NO}_{\mathrm{x}}$ also has a plethora of secondary effects. For example, the primary emission $\mathrm{NO}_{\mathrm{x}}$ is oxidized in the air or in cloud-water to form new, secondary compounds, which are acidic (particularly nitric acid) or which add to the ambient levels of oxidants, such as ozone. Emissions of $\mathrm{NO}_{\mathrm{x}}$ therefore present an acute problem, as they are a major precursor to ground-level ozone. Ozone has attracted a large amount of regulatory attention of late due to the limited progress that has been made to reduce ozone concentration levels. A second reason to analyze $\mathrm{NO}_{\mathrm{x}}$ emissions relates to data availability. Because of the numerous harmful effects of $\mathrm{NO}_{\mathrm{x}}$, EPA has compiled estimates of domestic emissions of $\mathrm{NO}_{\mathrm{x}}$ over the relatively lengthy period 1900-1994. A time-series of this length allows flexibility in 
the modeling approach and permits an examination of the exogenous factors that induced a change in the emission path, such as EPA mandates.

The emission data come from the National Air Pollutant Emission Trends (NAPET), 1900-1994, published by the EPA. The emission estimating methodologies for this time period fall into two major categories: 1900-1984 methodology and 1985-1994 methodology. Emission estimates from 1900-1984 are based on national estimates of economic activity, material flows, consumption of fuel, and in the case of combustion sources, fuel type used. Emissions for the years 19851994 are estimated using a "bottom-up" methodology where emissions are derived at the plant or county level and aggregated to the national level. Although a potential shortcoming regarding these data relates to combining indirect estimates with direct estimates, national emission estimates are largely unaffected by this methodological change due to the accuracy of the indirect approach. ${ }^{4}$ And, we should highlight that this methodological change occurred 15 years after 1970, the key date in our intervention analysis.

In light of our twin goal of analyzing the effects of the Clean Air Act of 1970 (denoted EPA mandates) and simultaneously examining the time-series properties of emissions, we use two methodologies to examine our time-series. First, we examine whether emissions contain the mean-reverting property after EPA mandates which took effect in 1970 is taken into consideration. ${ }^{5}$ If emissions are mean reverting, implications are that EPA policies did not permanently alter the long-run properties of $\mathrm{NO}_{\mathrm{x}}$ emissions. For this purpose, we employ unit root tests by allowing and not allowing for an intervention dummy variable. We then compare results from the unit root tests across these two specifications. The argument in the literature concerns the potential bias of unit root tests in the presence of a structural break-the unit root test is biased toward accepting the false unit root null when an existing structural break is ignored (see, e.g., Perron 1989; Amsler and Lee 1995). Thus, if two different results are drawn from different model specifications, the difference may contain important implications.

In our second approach, we employ the intervention analysis of Box and Tiao (1975) to determine whether EPA policies have had permanent and/or temporary effects on the growth rates, or levels, of emissions. The focus of the intervention analysis is not to examine the property of the time series as in the unit root test, but to take a close look at the nature of the policy changes. Thus, our intervention analysis is complementary to unit root tests. Intervention analysis has many important advantages. For example, upon EPA intervention it may be difficult to disentangle short- and long-term effects of EPA policies. This problem is handled naturally with the Box and Tiao approach, as the issue of whether the effects of EPA mandates are permanent, gradual, or temporary is self-contained in the model. We conclude by making use of our time-series models to calculate an upper bound of the amount of emissions saved due to the Clean Air Act of 1970. 


\section{Empirical Results}

We begin the empirical investigation by testing for a unit-root in $\log (\mathrm{NOX} 1){ }^{6}$ This preliminary analysis is necessary for two important reasons. First, standard inference of the time series model is potentially incorrect in the presence of a unit root-a relevant transformation of the time series is necessary to achieve a correct statistical inference if a unit root is present. Second, the existence of a unit root implies that the time series is difference stationary (DS). Whether a time series is DS or not has important implications. A time series that follows a DS process has tendencies to drift (upward or downward) over time exhibiting no trend-reversing properties. Thus, shocks to a variable following a DS process will have a permanent effect on the level of the variable. In contrast, if a time series follows a trend stationary (TS) process, it has tendencies to drift (upward or downward) over time exhibiting trend-reversing properties. The TS process would return to trend after shocks.

As a preliminary analysis, we examine the sample autocorrelation functions (ACF) of the data. Empirical results are reported in the Appendix B. They show slowly decaying ACFs, implying that the series appears difference stationary. Our first two empirical tests for stationarity are the augmented Dickey Fuller (ADF) unit root tests of Said and Dickey (1984) and the Phillips-Perron (Phillips and Perron 1989) (PP) unit root tests, which include a drift and/or a trend function. The ADF unit root tests are denoted as follows:

$$
y_{t}=\alpha+\psi \cdot t+\beta y_{t-1}+\sum_{j=1}^{k} c_{j} \Delta y_{t-j}+e_{t},
$$

where $\mathrm{y}_{\mathrm{t}}$ is the $\log$ of $\mathrm{NO}_{\mathrm{x}}$ per capita emissions at time $\mathrm{t} ; \alpha$ and $t$ are drift and trend components; $\mathrm{y}_{\mathrm{t}-\mathrm{j}}$ is the lagged value of $\mathrm{y}_{\mathrm{t}} ; \Delta \mathrm{y}_{\mathrm{t}-\mathrm{j}}$ is the lagged change in the log of $\mathrm{NO}_{\mathrm{x}}$ per capita emissions; $\mathrm{e}_{\mathrm{t}}$ is the well-behaved error term; and $\psi, \beta$, and $\mathrm{c}_{\mathrm{j}}$ are coefficients to be estimated. Equation (1) is the standard ADF test for a unit root and therefore if $\beta=1$, shocks to emissions are permanent and emissions have a unit root.

Our second unit root test is due to Phillips and Perron (1989), who make use of transformed statistics using the estimates of two error variances from the regression:

$$
y_{t}=\alpha+\psi \cdot t+\beta y_{t-1}+e_{t} .
$$

The innovation variance is estimated as the error sum of squares from the above regression. The long-run variance is estimated by choosing a truncation lag parameter $l$ and a set of weights $w_{j}, j=1, \ldots, l$ :

$$
\hat{\sigma}^{2}=\hat{\gamma}_{0}+2 \Sigma w_{j} \hat{\gamma}_{j}
$$

where $\hat{\gamma}_{j}$ is the jth sample autocovariance of the residuals from (2) and we use the Fejer kernel weight for $w_{j}$. Using these estimates of nuisance parameters, PP 

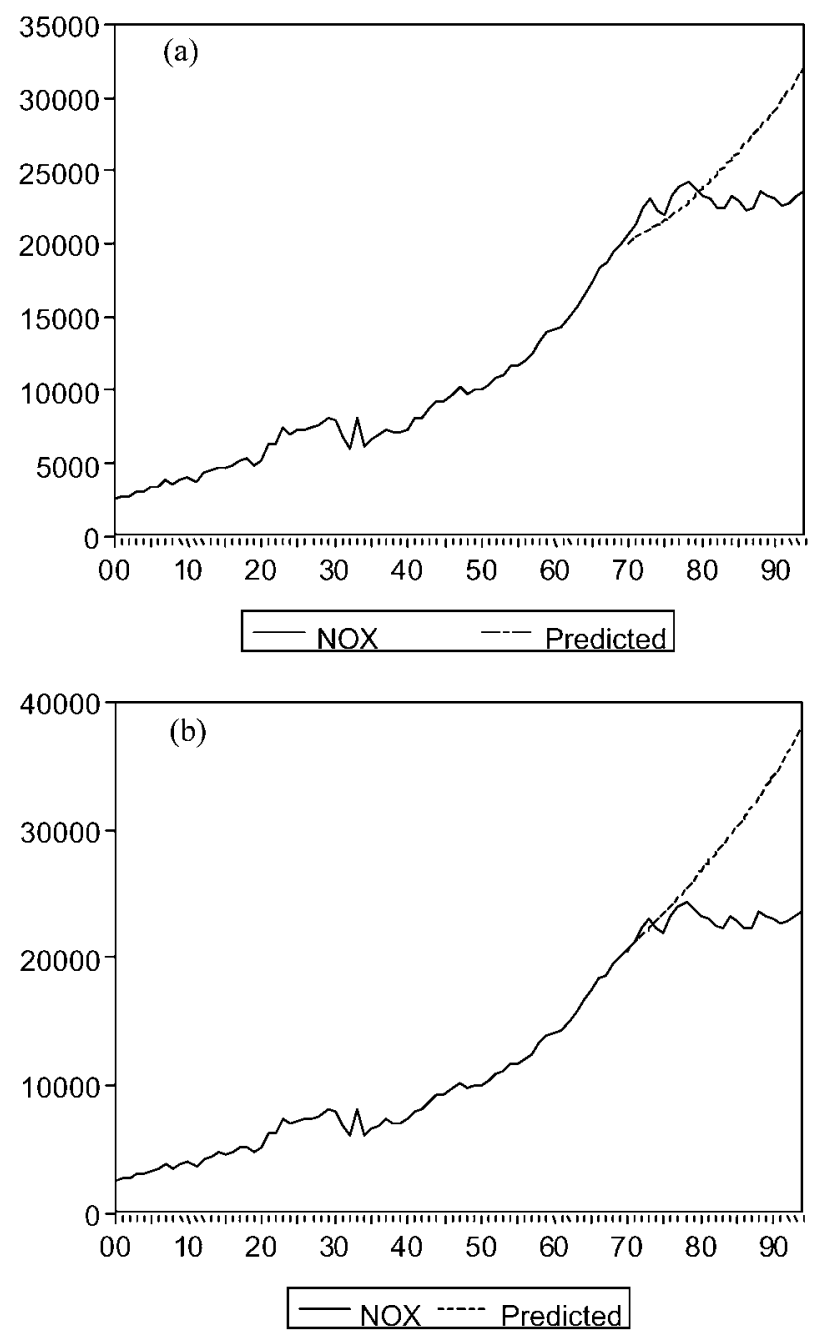

Figure 1. (a) Actual and predicted $\mathrm{NO}_{\mathrm{x}}$ emissions from ARMA models (case 1). (b) Actual and predicted $\mathrm{NO}_{\mathrm{x}}$ emissions from ARIMA models (case 2).

provide transformed tests of the Dickey-Fuller statistics. Precise definitions of the transformed PP statistics, $Z(\tau)$ and $Z(\alpha)$, are provided in PP (1989, p. 1382).

The plot of the data in Figures 1a and $\mathrm{b}$ indicate a trend function for $\log (\mathrm{NOX} 1)$. Nonetheless, we consider testing procedures with both types of models, one with trend, and the other with drift. Table I presents results of our initial unit root tests. Because results of the ADF tests depend on the number of augmentations, we consider various lags from 0 to 12 , and report results using 4, 8, and 12 augmentation lags. In addition, we compute the Akaike and Schwarz information criteria (AIC and BIC), and report these statistics for each model type. Overall, at the $P<$ 
Table I. Unit root tests without intervention

\begin{tabular}{|c|c|c|c|}
\hline & & \multicolumn{2}{|l|}{$\log (\mathrm{NOX} 1)$} \\
\hline & & With trend & With drift \\
\hline \multirow[t]{7}{*}{ ADF tests } & Augmentation lags & & \\
\hline & 0 & -2.84 & -1.92 \\
\hline & 4 & -1.84 & -1.80 \\
\hline & 8 & -2.60 & -1.66 \\
\hline & 12 & -1.93 & -1.71 \\
\hline & $\mathrm{AIC}^{\mathrm{a}}$ & $-1.71(1)$ & $-1.96(1)$ \\
\hline & $\mathrm{BIC}^{\mathrm{a}}$ & $-1.71(1)$ & $-1.96(1)$ \\
\hline \multirow[t]{5}{*}{ PP tests } & Truncation lags & & \\
\hline & 4 & -2.65 & -2.03 \\
\hline & 8 & -2.93 & -2.01 \\
\hline & 12 & -3.00 & -2.02 \\
\hline & Optimal lag b & $-2.43(3)$ & $-2.06(4)$ \\
\hline
\end{tabular}

${ }^{*}$ Significant at the $0 \%$ level; ${ }^{* *}$ significant at the $5 \%$ level; ${ }^{* * *}$ significant at the $1 \%$ level. ${ }^{\text {a }}$ Selected lags are given in parentheses.

${ }^{\mathrm{b}}$ Selected optimal bandwidth lags of Andrews (1991) are given in parentheses. The Fejer kernel was used for estimating the long-run variance.

Critical values of the ADF and PP tests at the $10 \%, 5 \%$, and $1 \%$ levels are $-3.155,-3.458$, -4.058 for models with trend, and $-2.583,-3.892,-3.501$ for models with drift.

0.05 level, our results suggest that we should not reject the null hypothesis of a unit root in all of the $\mathrm{ADF}$ tests.

The bottom panel of Table I presents results from the Phillips and Perron (1989) unit root tests. We employ 4, 8, and 12 truncation lags for the PP tests, and use the optimal bandwidth lags of Andrews (1991), and the Fejer kernel in estimating the long-run variance for the PP tests. Empirical results are essentially unchanged. Overall, the empirical findings suggest quite strongly that the $\mathrm{NO}_{\mathrm{x}}$ emission series is non-stationary, or contains a unit root. These results, however, were obtained by not taking into account of the potential structural change in 1970.

\subsection{HAVE EPA MANDATES INFLUENCED THE TIME SERIES?}

As previously mentioned, one test of EPA effectiveness is to examine whether the 1970 EPA mandates have permanent impacts on emissions. One way to achieve this goal is to analyze if the series is difference stationary after allowing for the policy dummy variables. We follow Park and Sung (1994), and consider the breaking slope and crash model which includes dummy variables $D_{t}$ and $B_{t}\left(=\Delta D_{t}\right)$, and $D T_{t}^{*}\left(=t \cdot D_{t}\right)$, in addition to a constant and a trend $(t)$ term in the ADF unit root testing regression (see Perron 1989). ${ }^{7}$ Park and Sung's (1994) test is similar in spirit 
Table II. Unit root tests with intervention

\begin{tabular}{lll}
\hline & & $\log (\mathrm{NOX} 1)$ \\
\hline Park and Sung's & Truncation lags & Breaking slope \& crash \\
PP-type tests & 4 & $-4.50^{* *}$ \\
& 8 & $-4.74^{* *}$ \\
& 12 & $-4.71^{* *}$ \\
& Optimal lag b & $-4.16^{*}(1)$ \\
\hline
\end{tabular}

${ }^{*}$ Significant at the $10 \%$ level; ${ }^{* *}$ significant at the $5 \%$ level; ${ }^{* * *}$ significant at the $1 \%$ level.

${ }^{\text {a }}$ Selected lags are given in parentheses.

${ }^{\mathrm{b}}$ Selected optimal bandwidth lags of Andrews (1991) are given in parentheses. The Fejer kernel was used in estimating the long-run variance.

${ }^{\mathrm{c} C r i t i c a l}$ calues of Perron's and Park and Sung's tests at the 10\%, 5\%, and $1 \%$ levels are $-3.86,-4.18,-4.75$ for models with breaking slope and crash.

${ }^{\mathrm{d}}$ We choose not to report all regression results for the above test to save space. But, as an illustration, we report below the estimated regression result for the case of using the twelve truncation lags.

$$
y_{t}=-1.044-0.324 y_{t-1}+0.004 t+0.024 B_{t}+0.042 D_{t}-0.007 D T_{t}
$$

to PP, except additional dummy variables are included in the testing regressions. As suggested by Park and Sung, the testing equations become:

$$
y_{t}=\alpha+\psi \cdot t+d_{0} B_{t}+d_{1} D_{t}+d_{3} D T_{t}^{*}+\beta y_{t-1}+e_{t},
$$

We note in passing that we do not need to include lagged augmented terms in the above equation since autocorrelated errors are controlled by the estimated longrun variance as in Equation (3). Table II presents empirical results for the unit root tests with intervention. While we report results using different truncation lags, we focus on estimates using the optimal bandwidth lag. In Table II, we see that we can reject the unit root hypothesis at the conventional $P<0.05$ level for each of the augmentation levels as well as the model using the optimal bandwidth lag at the $P<0.10$ level. ${ }^{8}$ Therefore, our findings show that while the emission series could be seen as non-stationary, it is now seen as trend-stationary when the structural break in 1970 is accounted for.

These findings may have important implications on model specifications for the large number of empirical studies that have regressed a measure of environmental quality on wealth (the environmental Kuznets curve (EKC) literature; see, e.g., List and Gallet (1999), and Grossman and Krueger (1995)). A brief review of the burgeoning EKC literature reveals that stationarity is assumed in the majority of studies. Our findings suggest that this assumption may be erroneous, and their conclusions are potentially misleading; the inverted U-shape association between pollution and wealth may be due to spurious correlation, given that pollution is seen as non-stationary if the structural change in 1970 is not accounted for. Thus, 
variables of interest may be seen as being neither purely stationary nor purely nonstationary. The inference also hinges on whether structural changes are modeled. Therefore, our results imply that if the environmental time series used in these studies have similar properties, a similar intervention term should be allowed. ${ }^{9}$

Most importantly, in light of our conjecture - if the data can be viewed as a mean-reverting process after allowing for policy dummy variables, then our empirical results strongly support the perceived effects that EPA had on emissions trends. ${ }^{10}$ Thus, we conclude that 1970 EPA mandates have permanent impacts on emissions and that they have been effective.

\subsection{HAVE EPA MANDATES HAD A PERMANENT EFFECT ON EMISSION LEVELS?}

Our second empirical method extrapolates information from the time series by using Box and Tiao's (1975) intervention analysis approach. One important advantage of this method is that we can examine whether EPA mandates had a permanent, abrupt, gradual, or temporary impact on emissions. As our above results indicate, $\log (\mathrm{NOX} 1)$ is a difference-stationary time-series, leading us to use the first difference data $\Delta \log (\mathrm{NOX} 1)$ to achieve stationarity for the intervention analysis. Despite this obvious choice of the first difference data, we also consider data in levels since $\log (\mathrm{NOX} 1)$ may be a trend stationary process after allowing policy dummy variables. We therefore consider two different models for the intervention analysis.

Our first model type is the ARIMA(p,1,q) model where the first differences of the data, $\Delta \log (\mathrm{NOX} 1)$, are used. Our second model type is the ARIMA(p,0,q) model where the level data, $\log (\mathrm{NOX} 1)$, are used. To facilitate estimation of the ARIMA models, we eliminate the deterministic portion of the time series by subtracting the mean of the first difference data, and de-trending the level data. The dummy variable coefficients in the analysis are therefore interpreted as deviations from the mean for the first differenced data and deviation from the trend function for the level data.

To estimate the intervention models, we consider the usual approach: ${ }^{11}$ identify the ARIMA models without intervention terms, and estimate the intervention models based on a priori identified models. For this task, we use the ITSM (Interactive Time Series Modelling) 6.0 software developed by Brockwell and Davis (1996) to identify and estimate the ARIMA models. For model identification purposes, we use the Akaike Information Criterion (AIC) to identify appropriate values of $p$ and $q$ in our $\operatorname{ARMA}(p, q)$ models. Using maximum likelihood estimates, we allow $p, q=0,1, \ldots, 4$, and choose $p$ and $q$ that minimize Akaike's AIC. We then use numerical optimization procedures to obtain maximum likelihood (ML) estimates of the parameters of our ARMA models, with selected orders $p$ and $q$ along with preliminary ML estimates. If fitted models are satisfactory, then the residuals should have the appearance of a realization of white noise. As a diagnostic 
check, we use the Portmanteau test of Box and Pierce, and other non-parametric tests for randomness of residuals. ${ }^{12}$ We find that the $\operatorname{ARIMA}(1,1,0)$ model provides a best fit for the logged, first difference data. For the level data, however, we find the ARIMA $(2,0,0)$ model is the superior choice.

We consider different specifications for permanent, gradual, and temporary impacts as follows:

$$
\phi(L) y_{t}=\frac{\omega(L)}{\delta(L)} Z_{1 t}+\frac{\varphi(L)}{c(L)} Z_{2 t}+\theta(L) u_{t}
$$

where $\phi(L)=1-\phi_{1} L-\ldots-\phi_{p} L^{p}, \omega(L)=\omega_{0}+\omega_{1} L+\ldots+\omega_{r} L^{r}, \varphi(L)=$ $\varphi_{0}+\varphi_{1} L+\ldots+\varphi_{n} L^{n}, \delta(L)=1-\delta_{1} L-\ldots-\delta_{m} L^{m}, c(L)=1-\delta_{1} L-\ldots-\delta_{s} L^{s}$, and $\theta(L)=1-\theta_{1} L-\ldots-\theta_{q} L^{q}$; and $L$ is a lag operator such that $L^{k} x_{t}=x_{t-k}$. Under this formulation, $\phi(L)$ and $\theta(L)$ denote the usual polynomials for the ARMA models, and $\omega(L)$ and $\varphi(L)$ are polynomials for the intervention terms. The polynomials $\delta(L)$ and $c(L)$ capture gradual impacts of EPA intervention. The variable $\mathrm{y}_{\mathrm{t}}$ represents $\Delta \log (\mathrm{NOX} 1)$ for the first difference data, and represents $\log (\mathrm{NOX} 1)$ for the level data. The first term on the right hand side includes the intervention terms, where $Z_{1 t}$ and $Z_{2 t}$ denote the exogenous policy variables. We define $D_{t}=1$ for $t \geq 1970$, and 0 otherwise; and $B_{t}=1$ for $t=1970$, and zero otherwise. We also define $D T_{t}^{*}=t$ for $t \geq 1970$, and 0 otherwise. The coefficient of the one-time dummy variable $B_{t}$ captures temporary changes that tend to disappear quickly, while the coefficient of $D_{t}$ captures the changed mean of the time series after the intervention.

For the $\operatorname{ARIMA}(p, 1, q)$ model using the first difference data, $Z_{1 t}$ includes the policy dummy variables such that $Z_{1 t}=D_{t}$ for the permanent effects of interventions, while $Z_{2 t}$ is not included. To capture the temporary impacts, we set $Z_{1 t}=B_{t}$, and $Z_{2 t}$ is absent; therefore $\omega_{i}$ and $\delta_{i}$ estimate the initial abrupt impact and the gradual dynamic response of an event of the observed time series. For the $\operatorname{ARIMA}(p, 0, q)$ model using the level data, $Z_{1 t}=D_{t}$, and $Z_{2 t}=D T_{t}^{*}$ are used to examine the permanent effect of interventions. The temporary effects are not meaningful here and therefore ignored, when they are absorbed in the permanent changes. In this case, $\omega_{i}$ and $\delta_{i}$ estimate the initial abrupt impact and the gradual dynamic response of an event on the level of the observed time series, whereas $\varphi_{\mathrm{i}}$ and $c_{i}$ capture the same effects on the trend shift of the observed time series.

We first discuss the results of the intervention analysis with the $\operatorname{ARIMA}(p, 1, q)$ specifications, for which the first difference data, $\Delta \log (\mathrm{NOX} 1)$, are used. Table III presents these results. The results indicate that the estimated coefficients of $\omega_{0}$ are insignificant at conventional levels in all four model types. In models (A) and (B), this finding suggests that abrupt impacts are not significant, while interpretations from models (C) and (D) are that gradual effects are insignificant. The coefficients of $\delta_{1}$ and $\delta_{2}$ are, however, significant at conventional levels for both permanent and temporary changes. ${ }^{13}$ This result implies that EPA mandates had gradual effects on emission flows. Examining the magnitude of these coefficients, 
Table III. Intervention analysis with $\operatorname{ARIMA}(\mathrm{p}, 1, \mathrm{q})$ specification

\begin{tabular}{lllll}
\hline \multirow{2}{*}{$\log (\mathrm{NOX} 1)$} & \multicolumn{4}{l}{$\operatorname{ARIMA}(1,1,0)$ with interventions } \\
\cline { 2 - 5 } & $\phi_{1}$ & $\omega_{0}$ & $\delta_{1}$ & $\delta_{2}$ \\
\hline (A) Abrupt \& Permanent & $-0.389^{*}$ & -0.014 & & \\
$Z_{1 t}=D_{t}, \delta_{i}=0$ & $(-4.03)$ & $(-1.58)$ & & \\
(B) Abrupt \& Temporary & $-0.373^{*}$ & 0.012 & & \\
$Z_{1 t}=B_{t}, \delta_{i}=0$ & $(-3.84)$ & $(0.209)$ & & \\
(C) Gradual \& Permanent & $-0.395^{*}$ & -0.002 & $1.92^{*}$ & $-0.962^{*}$ \\
$Z_{1 t}=D_{t}, \delta_{i} \neq 0$ & $(-4.04)$ & $(-0.495)$ & $(4.27)$ & $(-2.30)$ \\
(D) Gradual \& Temporary & $-0.380^{*}$ & 0.020 & $0.992^{*}$ & $-0.937^{*}$ \\
$Z_{1 t}=B_{t}, \delta_{i} \neq 0$ & $(-3.84)$ & $(0.744)$ & $(5.64)$ & $(-3.95)$ \\
\hline
\end{tabular}

${ }^{*}$ Significant at the $5 \%$ level. Numbers in parentheses are $t$-statistics.

Table IV. Intervention analysis with $\operatorname{ARIMA}(\mathrm{p}, 0, \mathrm{q})$ specification

\begin{tabular}{llllllll}
\hline $\log (\mathrm{NOX} 1)$ & \multicolumn{6}{l}{$\operatorname{ARIMA}(2,0,0)$} & with interventions \\
\cline { 2 - 7 } & $\phi_{1}$ & $\phi_{2}$ & $\omega_{0}$ & $\delta_{1}$ & $\varphi_{0}$ & $c_{1}$ \\
\hline (A) Abrupt \& permanent & $0.517^{*}$ & $0.295^{*}$ & $0.871^{*}$ & & $-0.018^{*}$ & \\
$Z_{1 t}=D_{t}, Z_{2 t}=D T_{t}^{*}, \delta_{i}=0, c_{i}=0$ & $(5.0)$ & $(2.9)$ & $(2.6)$ & & $(-2.7)$ & \\
$(\mathrm{C})$ Gradual \& permanent & $0.483^{*}$ & $0.285^{*}$ & 0.130 & $0.861^{*}$ & -0.001 & 0.911 \\
$Z_{1 t}=D_{t}, Z_{2 t}=D T_{t}^{*}, \delta_{i} \neq 0, c_{i} \neq 0$ & $(4.7)$ & $(2.8)$ & $(0.05)$ & $(4.2)$ & $(-0.03)$ & $(0.56)$ \\
\hline
\end{tabular}

* Significant at the 5\% level. Numbers in parentheses are $t$-statistics.

we observe that their sum is close to zero for the model with gradual and temporary effects, implying that their effects will cancel out in the long run. Alternatively, there is no such cancellation effect in the model with gradual and permanent effects. Combining these results, we conclude that EPA intervention had gradual and permanent changes on the growth rates of per capita $\mathrm{NO}_{\mathrm{x}}$ emissions. ${ }^{14}$

Table IV presents empirical results from models using the level data. In this model, the estimated coefficients of $\omega_{0}$ and $\varphi_{0}$ in the abrupt and permanent model are significant at conventional levels. This result implies that EPA mandates have led to an abrupt change in the level of emissions of $\mathrm{NO}_{\mathrm{x}}$ as well as an abrupt change in its trend. Next, we observe that the estimated coefficient of $\delta_{1}$ is highly significant in the gradual and permanent model while the estimated coefficient of $c_{1}$ is insignificant. As such, we conclude that EPA mandates had gradual and permanent effects on the level of emissions, but the change in its trend is not gradual. ${ }^{15}$

In sum, our results suggest that the events surrounding 1970 led to gradual and permanent changes on the $\mathrm{NO}_{\mathrm{x}}$ emission time path. This makes sense, as one would expect that $\mathrm{NO}_{\mathrm{x}}$ emissions would take time to adjust to the new rules and 
regulations imposed in the 1970 Clean Air Act (CAA). The 1970 CAA contained a number of key provisions. Given that motor vehicle emissions and fuel combustion accounted for approximately $85 \%$ of all $\mathrm{NO}_{\mathrm{x}}$ emissions in 1970, the main provisions for our purposes entail reductions from these types of sources. Concerning the former, the 1970 CAA called for "at least a 90 per centum [reduction] from the average of emissions of oxides of nitrogen actually measured from light duty vehicles manufactured during model year 1971" (CAAA, PL 91-604, p. 1690). To achieve this goal, the EPA stated that emissions standards must be met 5 years or 50,000 miles after vehicle purchase. Given that highway vehicle emissions depend on fuel type, vehicle type, technology, and extent of travel, and that vehicle activity levels are related to changes in economic conditions, fuel prices, cost of regulations, and population characteristics, emissions are a function of vehicle activity levels and emission rates per unit activity. A gradual change in emissions from onroad vehicles is therefore expected since the turnover rate in the motor-vehicle fleet is not instantaneous.

The second major source of $\mathrm{NO}_{\mathrm{x}}$ in the US is fuel combustion by industrial and electric utilities. The 1970 CAA also allowed for a gradual decrease in emissions from these sources. In particular, EPA established National Ambient Air Quality Standards for each criteria air pollutant. For $\mathrm{NO}_{\mathrm{x}}$, the primary standard was initially 0.053 PPM annual mean (maximum human exposure). The EPA created emissions limits and monitoring for stationary sources to meet these criteria within due time, allowing $\mathrm{NO}_{\mathrm{x}}$ emitters to gradually meet requirements.

\subsection{HOW MUCH HAS BEEN SAVED DUE TO THE CLEAN AIR ACT OF 1970?}

Given that our results suggest that EPA mandates had a permanent effect on emission flows, an exploratory probe can be conducted to calculate how large of an effect EPA has had on reductions of $\mathrm{NO}_{\mathrm{x}}$ emissions, if one attributed all of the emissions reductions to regulatory policy. The EPA recently estimated the retrospective costs and benefits of the 1970 CAA between 1970-1990. ${ }^{16}$ This analytically intensive self-evaluation found that Federal regulatory actions led to substantial savings in criteria air pollutants. This section reconsiders how Federal intervention affected estimated savings in nitrogen oxides during the regulatory era. We employ the ARIMA forecasting models to examine this issue. We estimate ARIMA models using emission data from pre-EPA mandate years - 1900 to 1969 - to obtain outside sample forecasts for 1970 to 1994 . We compare these outside sample forecasts with actual values of emissions. Akin to EPA (1997), we assume that the emission time series would have followed the patterns of the outside sample forecasts absent EPA mandates. By doing so, we assume that the differences between the outside forecasts and actual values are due to EPA mandates.

The first important problem in such an exercise is to find the most appropriate $\operatorname{ARIMA}(p, d, q)$ model to represent the time series. As elaborated on above, since the time series involves both deterministic and stochastic trends, a transformation 
Table V. Estimated ARMA models

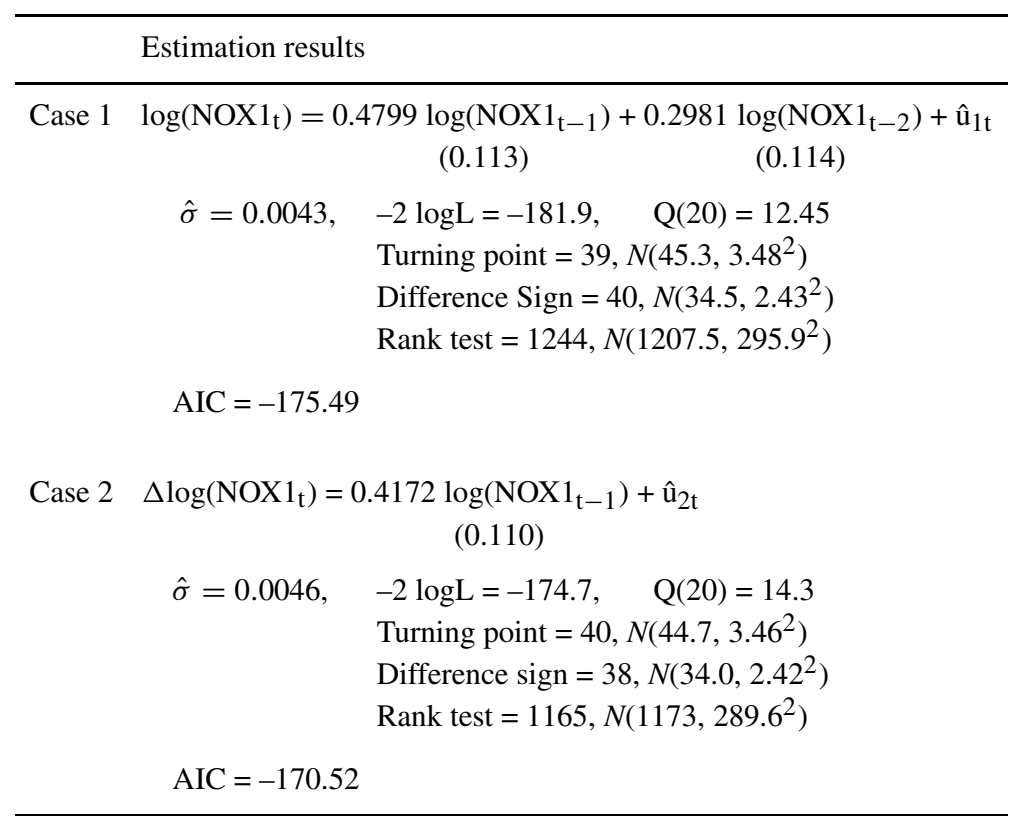

to produce a new stationary series with mean zero is obligatory. Since the series contains a unit root, we use first differences $(d=1), \Delta \log \left(\mathrm{NOX} 1_{\mathrm{t}}\right)$ to eliminate any stochastic trends. For comparison purposes, we also use the level data $(d=0)$, $\log \left(\mathrm{NOX} 1_{\mathrm{t}}\right) \cdot{ }^{17}$ We follow a similar procedure to identify appropriate values of $p$ and $q$ in our ARMA $(p, q)$ models. The ML estimates corresponding to the selected orders, and test statistics for randomness of residuals are in Table V. Results in Table $\mathrm{V}$ provide vivid evidence of model appropriateness-all coefficients in the ARMA models are significant at conventional levels. Furthermore, for each test and for all residuals, we cannot reject the null hypothesis of a white noise process. This is compelling evidence that the model is a "good fit" for our data.

Our next step is to compute best linear $h$-step predictors by using the estimated model to predict values from 1970 to 1994 . Since the prediction is established with transformed data, a transformation inversion is necessary to fit a zeromean stationary model. Relevant inverted transformations include de-trending, de-differencing, and taking exponentials of the logged series. The inverted transformation allows us to obtain predicted values in original form, allowing a comparison between forecasted emissions and actual values. Since our data are measured as emissions per capita, we again multiply by US population to evaluate emissions and reductions in emissions.

Figures 1a and $\mathrm{b}$ display plots of forecasted emissions, actual emissions, and their differences, for each estimated model, where case 1 is based the ARMA 
Table VI. Comparison of emission savings (percent of total) for selected years ${ }^{\mathrm{a}, \mathrm{b}}$

\begin{tabular}{|c|c|c|c|c|c|c|c|c|c|}
\hline \multirow[t]{2}{*}{ Pollutant } & \multicolumn{4}{|c|}{ EPA quinqennial estimates } & & \multicolumn{4}{|c|}{ Our quinqennial estimates } \\
\hline & 1975 & 1980 & 1985 & 1990 & & 1975 & 1980 & 1985 & 1990 \\
\hline \multirow[t]{2}{*}{$\mathrm{NO}_{\mathrm{x}}$} & 2.73 & 9.52 & 20.78 & 28.53 & Case 1 & -1.44 & 2.07 & 14.90 & 26.70 \\
\hline & & & & & Case 2 & 7.13 & 14.74 & 32.16 & 48.44 \\
\hline
\end{tabular}

\footnotetext{
aAlthough our model porvides annual savings, the EPA's estimates are quinqennial, from which they linearly interpolate other years. For the sake of comparison, therefore, we also only report quinquennial figures.

${ }^{b}$ The percentage of emissions saved for both the EPA and our estimates are calculated using the following rule: $\left(\mathrm{NC}_{\mathrm{it}}-\mathrm{C}_{\mathrm{it}}\right) / \mathrm{NC}_{\mathrm{it}}$; where $\mathrm{NC}_{\mathrm{it}}\left(\mathrm{C}_{\mathrm{it}}\right)$ represents the no-control (control) estimate of emission $\mathrm{i}$ in time period $\mathrm{t}$.

${ }^{\mathrm{c}}$ Case 1 is using level data and case 2 uses difference data.
}

model in level and case 2 is based on the ARIMA model in difference. An important finding is that we observe predicted values absent EPA mandates to be considerably above actual emissions levels after 1970. The difference between these two trends is considered the emissions saved due to the 1970 CAA. We summarize the mean emissions reductions for 1970-1990 in Table VI. Also in Table VI are quinquennial estimates of saving figures from EPA's (1997) self-assessment. Comparison of empirical results shows that the estimate from Case 1 using the level data is very close to estimates from EPA's assessment. This assertion is based on the fact that EPA quinqennial estimates of emissions saved over the period 1975-1990 are 2.73, 9.52, 20.78, and 28.53 whereas comparable estimates from case 1 are 1.44, 2.07, 14.90 , and $26.70 .{ }^{18}$ Somewhat surprising is the fact that our relatively simple procedures produced estimates that closely resemble EPA's savings figures computed from very analytically intense methods. Meanwhile, the estimated emissions saved from case 2 using the differenced data are nearly $48 \%$. In this case, the estimated savings are much higher compared to estimates from the model based on the level data.

Accuracy of predicting pollution paths has far reaching implications, such as aiding in the development of optimal abatement strategies and multi-lateral bargaining strategies. In our analysis of $\mathrm{NO}_{\mathrm{x}}$ emissions, two quite different predictions are provided from our models, which are not atypical (see, e.g., Diebold and Senhadji 1996; Diebold and Kilian 1999). The results suggest that trend- and difference-stationary models of the same time series often provide different point forecasts, and that pre-testing improves forecasting accuracy relative to routinely differencing or using level data. Following Diebold and associates, we are inclined to adopt the estimates based on the model using the differenced data, since the pretesting result indicates that the time path before 1970 EPA mandates is difference stationary. Consequently, EPA's estimated savings figures for $\mathrm{NO}_{\mathrm{x}}$ are lower than our preferred estimates. 


\section{Concluding Remarks}

Before commencing a rigorous assessment of theory or specifying an econometric model, a thorough investigation of the time series properties of the data has become almost second-hand amongst many economists. Yet to date little has been done to further our understanding of our own time series data, where a proper understanding of certain time series is invaluable to forward optimal policy prescriptions. As an illustrative case study, we present a battery of tests on US $\mathrm{NO}_{\mathrm{x}}$ emission data from 1900-1994 to provide a first examination of its time-series properties. Our analysis both highlights recent time series innovations and provides many new insights.

First, in certain respects, our empirical results suggest that $\mathrm{NO}_{\mathrm{x}}$ emissions can be seen as being neither purely stationary nor purely non-stationary. The inference hinges on whether EPA mandates are accounted for or not. This finding is fundamentally important when developing appropriate modeling strategies to verify theories of optimal abatement strategies. Second, we find that the relationship between EPA mandates and $\mathrm{NO}_{\mathrm{x}}$ emissions are of a deep nature, such that changes in EPA mandates have had a permanent effect on the path of $\mathrm{NO}_{\mathrm{x}}$ emissions. This finding speaks well of recent EPA policies, and refutes the argument that governmental mandates have a transitory effect, or influence only the temporary component of long-run pollution trends. We conclude by estimating emission savings figures due to the 1970 Clean Air Act. Our estimates are consonant with EPA's recent estimates-verifying the premise that the US has avoided about $48 \%$ of $\mathrm{NO}_{\mathrm{x}}$ emissions due to the Clean Air Act of 1970. Yet a major caveat in our approach is that we are attributing all of the emissions reductions to regulatory policy. An appropriate next step in this line of research is to parse out other potentially significant events to provide a "cleaner" estimate of the emissions saved.

\section{Acknowledgements}

We thank Craig Gallet and Mark Strazicich for very helpful comments.

\section{Notes}

1. For exceptions, see recent studies of metals use and resource commodity prices (e.g., Labson and Crompton (1993), Labson (1995), and Ahrens and Sharma (1997)), and on the study of fisheries economics Mkenda et al. (2001).

2. In their seminal paper, Nelson and Plosser (1982) suggest that most variation from shocks or innovations to macroeconomic time series is due to a (non-stationary) permanent or random walk component, with little variation attributed to a (stationary) temporary cyclical component. We follow Beverage and Nelson (1981) and estimate each of permanent and transitory components of the per-capita $\mathrm{NO}_{\mathrm{x}}$ series. It has been found that the permanent component dominates (higher than $97 \%$ at almost all time periods) in the $\mathrm{NO}_{\mathrm{x}}$ series; the plot of the permanent and temporary components in the per-capita $\mathrm{NO}_{\mathrm{x}}$ is provided in the Appendix.

3. An anonymous referee points out convincingly that it may not be credible to treat all deviations below a trend of emissions are reduced as a result of the Clean Air Act of 1970. The oil price 
shock of 1973 and its resultant effect on technological change to save energy intensive sources might have contributed to the structural change in $\mathrm{NO}_{\mathrm{x}}$ emissions. Given a short time interval between the 1970 CAA and the 1973 oil shock and the changes might have been made gradually, it is difficult to decompose empirically the effects of each of these events. In a nutshell, our estimates reflect all of these mixed effects and when presenting estimates below it is important to note that we are attributing all of the emissions reductions to regulatory policy.

4. See List (1999) for a more thorough discussion of the $\mathrm{NO}_{\mathrm{x}}$ data.

5. We follow EPA's (1997) self-assessment and analyze how EPA mandates affected emission flows after 1970 .

6. We transformed the data by taking the logarithms of per-capita emissions: $\log (\mathrm{NOX} 1)=$ $\log \left(\mathrm{NO}_{\mathrm{X}} /\right.$ Population $)$. This data transformation does not influence the main results, but using logged data will typically reduce data fluctuations.

7. Following EPA (1997), we set $D_{t}=1$, for $t \geq 1970$, and $=0$ otherwise.

8. Here, the augmented version of the Perron's test can be alternatively used. But, the PP-type tests are known to be more powerful. Furthermore, given that the break year is known, and has been exogenously imposed, we do not have to consider the so-called endogenous unit root tests in which break points are determined from the data.

9. We are not aware of any EKC studies that take into account these two factors at the same time.

10. Our result is reinforced by the unit root test results applied to the pre-1970 data-test results using the 1901-1970 (or 1901-1960) data, not shown here to conserve space, indicate the presence of a unit root.

11. We also considered joint model identification by determining the orders of the ARMA and intervention terms. This method appears a superior choice, but the ARIMA model estimations from this method often fail because the models are not causal. Thus, we adopt a two-step procedure: i) identify the orders of the ARMA terms; ii) identify orders of intervention terms based on $a$ priori specified ARIMA models.

12. These include the turning points test, the difference sign test, and the rank test (Brockwell and Davis 1991).

13. To identify the maximum orders for $\delta(L)$, we considered different orders and found that using two lags was most appropriate.

14. Note that the dynamic multiplier is given as the sum of these coefficients. Also note that we are using first differences of the logged data; thus it is appropriate to speak of changes in growth rates.

15. Based on the magnitude of the estimated coefficient of $\delta_{1}$, we can say, for instance, that even after 5 years the gradual effect is still significant with $0.13 \times 0.861^{5}=0.13 \times 0.0473$ since $0.13 /(1-0.861)=0.13 \times\left(0.861+0.861^{2}+0.861^{3}+0.861^{4}+0.861^{5}+\ldots\right)$.

16. Section 812 of the CAAA of 1990 requires the EPA to assess periodically the effect of the Clean Air Act on the "public health, economy, and environment of the United States", and to report subsequent findings to the Congress (EPA 1997).

17. Inspection of the graph of the series reveals that a linear trend is included in $\log \left(\mathrm{NOX} 1_{\mathrm{t}}\right)$. Thus, we detrend the series with a linear trend function in modeling the logged data, and use the transformed series in estimating ARMA models. For the first difference series, a trend function may not be necessary; thus, we demean the series with a drift term before estimating ARMA models.

18. The percentage of emissions saved for both the EPA and our estimates are calculated using the following rule: $\left(\mathrm{NC}_{\mathrm{it}}-\mathrm{C}_{\mathrm{it}}\right) / \mathrm{NC}_{\mathrm{it}}$; where $\mathrm{NC}_{\mathrm{it}}\left(\mathrm{C}_{\mathrm{it}}\right)$ represents the no-control (control) estimate of $\mathrm{NO}_{\mathrm{x}}$ in time period $\mathrm{t}$. 


\section{References}

Ahrens, W. and V. Sharma, (1997), 'Trends in Natural Resource Commodity Prices: Deterministic or Stochastic?' Journal of Environmental Economics and Management 16, 184-192.

Amsler, C., and J. Lee (1995), 'An LM Test for a Unit Root in the Presence of a Structural Change', Econometric Theory 11, 359-368.

Andrews, D. W. K. (1991), 'Heteroskedasticity and Autocorrelation Consistent Covariance Matrix Estimation', Econometrica 59, 817-858.

Beveridge, S. and C. Nelson (1981), 'A New Approach to Decomposition of Economic Time Series into Permanent and Transitory Components with Particular Attention to Measurement of the 'Business Cycle' ', Journal of Monetary Economics 7, 151-174.

Box, G. E. P. and G. C. Tiao (1975), 'Intervention Analysis with Applications to Economic and Environmental Problems', Journal of the American Statistical Association 70, 70-79.

Brockwell, P. J. and R. A. Davis (1991), Time Series: Theory and Methods. New York: SpringerVerlag Pub. Co.

Brockwell, P. J. and R. A. Davis (1996), ITSM: An Interactive Time Series Modeling Package for Windows. New York: Springer-Verlag.

Clean Air Act Amendments, Document \#PL 91-604, Washington, DC.

Diebold, F. X. and L. Kilian (1999), 'Unit Root Tests are Useful for Selecting Forecasting Models', National Bureau of Economic Research Working Paper: 6928.

Diebold, F. X. and A. S. Senhadji (1996), 'Deterministic vs. Stochastic Trend in US GNP: Comment', American Economic Review 86, 1291-1298.

Environmental Protection Agency (1997), 'The Benefits and Costs of the Clean Air Act, 1970 to 1990', prepared for US Congress. Washington, DC. Draft.

Grossman G. and A. Krueger (1995), 'Economic Growth and the Environment', Quarterly Journal of Economics 3 (May), 53-77.

Labson, B. S. (1995), 'Stochastic Trends and Structural Breaks in the Intensity of Metals Use', Journal of Environmental Economics and Management 29, S34-S42.

Labson, B. S. and P. L. Crompton (1993), 'Common Trends in Economic Activity and Metals Demand: Cointegration and the Intensity of Use Debate', Journal of Environmental Economics and Management 25, 147-161.

List, J. (1999), 'Have Air Pollutant Emissions Converged Amongst US Regions? Evidence from Unit-Root Tests', Southern Economic Journal 66, 144-155.

List, J. and C. Gallet (1999), 'The Environmental Kuznets Curve: Does One Size Fit All?' Ecological Economics 31(3), 409-423.

Mkenda, A. F. and H. Folmer (2001), 'The Maximum Sustainable Yield of Artisanal Fishery in Zanzibar: A Cointegration Approach', Environmental and Resource Economics 19 (August), 311-328.

NAPET (1995), 'US Environmental Protection Agency, Office of Air Quality Planning and Standards, 1929-1994', National Air Pollutant Emission Trends. Washington, DC.

Nelson, C. R. and C. I. Plosser (1982), 'Trends and Random Walks in Macroeconomic Time Series', Journal of Monetary Economics 10, 139-162.

Park, J. Y. and J. Sung (1994), 'Testing for Unit Roots in Models with Structural Change', Econometric Theory 10 (December), 917-936.

Perron, P. (1989), 'The Great Crash, The Oil Price Shock, And The Unit Root Hypothesis', Econometrica 57, 1361-1401.

Phillips, P. C. B. and P. Perron (1988), 'Testing for a Unit Root in Time Series Regression', Biometrika 75(2), 335-346.

Said, S. E. and D. A. Dickey (1984), 'Testing for Unit Roots in Autoregressive-Moving Average Models of Unknown Order', Biometrika, 599-608. 
Appendix A

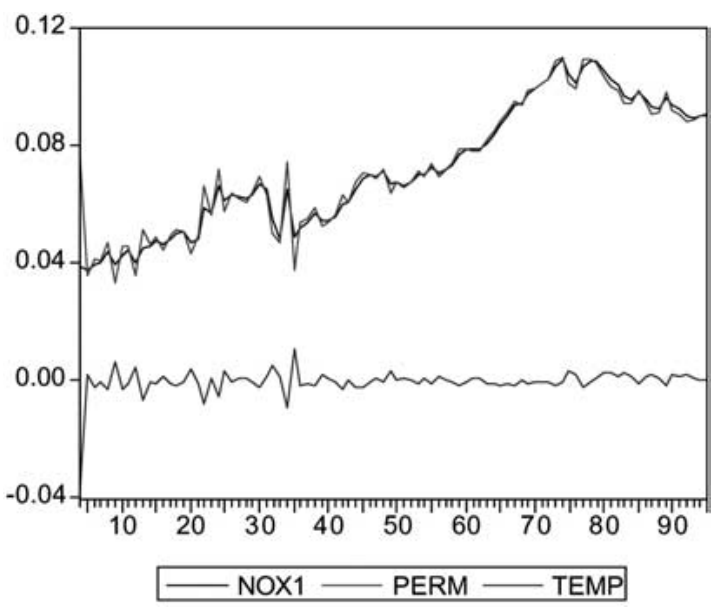

Permanent (PERM) and temporary (TEMP) components of the per-capita $\mathrm{NO}_{\mathrm{X}}$.

Appendix B

\begin{tabular}{rrrcl}
\hline \multicolumn{5}{c}{ Correlogram of NOX1 } \\
\hline Lags & ACF & PACF & Q-stat & $P$-value \\
\hline 1 & 0.965 & 0.965 & 91.264 & 0.000 \\
2 & 0.939 & 0.111 & 178.55 & 0.000 \\
3 & 0.911 & -0.016 & 261.69 & 0.000 \\
4 & 0.885 & 0.001 & 340.96 & 0.000 \\
5 & 0.851 & -0.121 & 415.10 & 0.000 \\
6 & 0.818 & -0.028 & 484.41 & 0.000 \\
7 & 0.785 & -0.031 & 548.86 & 0.000 \\
8 & 0.752 & -0.002 & 608.82 & 0.000 \\
9 & 0.713 & -0.114 & 663.23 & 0.000 \\
10 & 0.678 & 0.030 & 713.10 & 0.000 \\
11 & 0.644 & -0.001 & 758.58 & 0.000 \\
12 & 0.609 & -0.033 & 799.74 & 0.000 \\
13 & 0.572 & -0.029 & 836.53 & 0.000 \\
14 & 0.540 & 0.023 & 869.66 & 0.000 \\
15 & 0.506 & -0.022 & 899.17 & 0.000 \\
16 & 0.471 & -0.055 & 925.03 & 0.000 \\
17 & 0.432 & -0.065 & 947.11 & 0.000 \\
18 & 0.397 & -0.011 & 965.98 & 0.000 \\
19 & 0.364 & 0.017 & 982.03 & 0.000 \\
20 & 0.328 & -0.046 & 995.26 & 0.000 \\
\hline
\end{tabular}


